\title{
Exposure Analysis of Electromagnetic Shield Effect of a Copper Composite Cloth Structure
}

\author{
Bosiljka ŠARAVANJA ${ }^{1}$, Krešimir MALARIĆ ${ }^{2}$, Tanja PUŠIĆ ${ }^{3}$, Darko UJEVIĆ ${ }^{4}$ \\ ${ }^{1,4}$ University of Zagreb Faculty of Textile Technology, Department for Clothing Technology, 10000 Zagreb, Croatia \\ 2 University of Zagreb Faculty of Electrical Engineering and Computing, Department of Radio-communications, 10 000Zagreb, Croatia \\ 3 University of Zagreb Faculty of Textile Technology, Department for Textile Chemistry \& Ecology, 10000 Zagreb, Croatia
}

Corresponding Author: Bosiljka Šaravanja, bosiljka.saravanja@ttf.hr

\begin{abstract}
The electromagnetic (EM) protection factor is defined as a ratio of EM field intensity measured without the shielding material and field intensity with the shielding material placed between EM radiation source and receiver. This research is focused on SE durability of the composite cloth structure, where the functional interlining polyamide fabric coated with copper IF was integrated, after exposure to heat and moisture in steam-setting, ironing and double compressing. The cloth composite structure was also exposed to solvent in dry cleaning. It was proved that a synergy of thermal and mechanical actions in ironing and pressing caused a drop of SE in the frequency range from 0.9 to $2.4 \mathrm{GHz}$. Increased number of dry cleaning cycles resulted in further reduction of protective properties. Cross section and chemical analysis of IF before and after 10 dry cleaning cycles are not harmonized with low durability of SE properties in dry cleaning.
\end{abstract}

\author{
ARTICLE HISTORY \\ Received: 03.10.2019 \\ Accepted: 20.05.2020

\section{KEYWORDS} \\ Composite cloth structure, \\ interlining fabric with copper, \\ electromagnetic shield, heat, \\ moisture, solvent
}

\section{INTRODUCTION}

Fields and waves of wireless technology (GSM or Global System of Mobile Communications, WLAN etc) are nonionising microwave electromagnetic (EM) radiations [1]. Frequent usage of electronic devices can impact human health and cause problems, such as behavior changes, high stress level, insomnia, heart arrhythmia etc. Investigation of EM radiation (GSM, microwave ovens, etc.) impact on laboratory rats have confirmed supposed changes in their metabolism, brain functioning and activities of the nervous system [2-4]. EM waves in organism cause molecules vibration so that they release heat, at the same time preventing or disable DNA and RNA cell regeneration [5]. The impact on metabolic activities results in increased danger of various cancerous diseases, as proved by different medical investigations [6-9]. Epidemiologic investigations have been dealing with possible higher risks of certain types of tumors of various parts of head with regular users of cell phones and GSM devices.
Intensive technological development of new electric and electronic devices and gadgets, demand for more intensive control of the negative impact of the technology and ways of their preventions. This is why limits have been set to EM emissions for all electric and electronic devices, in order to minimize the possibility of radio and wireless communications interfering with human and other organisms. Among numerous other solutions, textile materials and products, as well as textile composite materials, have attracted considerable attention, primarily due to their diversified and comprehensive application [10]. Intensive development of textile products with EM shield effect properties has attracted considerable interest of researchers, textile and garment industries that have been trying to manufacture woven or knitted fabrics, as well as garment items with EM shield effect properties [11-13]. Some studies of knitted fabrics of various structures, manufactured on flat knitting machines using rust free and copper wires, have shown that fabrics made of double wires exhibit considerably higher EM shield effect properties [14,

To cite this article: To cite this article: Šaravanja B, Malarić K, Pušić T, Ujević D. 2020. Exposure Analysis of Electromagnetic Shield Effect of a Copper Composite Cloth Structure. Tekstil ve Konfeksiyon, 30(2), 138-143. 
15]. Numerous investigations have been led to protect human body from EM radiation with textiles (both woven and knitted) developed with SE properties, together with the composite structures with conductive materials $(\mathrm{Cu}, \mathrm{Ag}$, Ti, Ni etc) [16, 17].

Some conductive light and flexible textile surfaces with favorable effect can provide protection from EM radiation and replace electro conductive metal products or protective materials manufactured from wire nets for various protective purposes in electric and electronic industries [18].

Investigation of material composition, presence of metal, density, yarn count, porosity and number of layers impact on EM shield properties of woven fabrics indicated that SE was increased with more layers, yarn count reduction (yarn be-come coarser) and metals present on the fabric $[19,20]$.

EM interferences (EMI) have become a serious problem in various pieces of electronic equipment, such as personal computers (several GHz), mobile devices $(0.9 \mathrm{GHz}-2.4$ $\mathrm{GHz}$ ) as well as in other devices and equipment [21].

Study of EM shielding ability of metal-containing woven and knitted fabrics after washing and drying proved that both withstood satisfactory repeated maintenance protocol with respect to this protection requirement [22].

The aim of this study is investigation of the EM shield effect and efficiency of a multilayered the composite cloth structure composed from basic fabric, adhesive interlining fabric (IF), functional IF coated with copper and lining fabric at the frequencies of $0.9 \mathrm{GHz}, 1.8 \mathrm{GHz}, 2.1 \mathrm{GHz}$ and $2.4 \mathrm{GHz}$ before and after exposure to heat and moisture in production and solvent in a maintenance.

\section{MATERIALS AND METHODS}

\subsection{Materials and processes}

Interlining fabric coated with copper (IF) is recommended for pockets of men's jackets, trousers and other items of clothing, where it is supposed for protection from detrimental impact of microwave radiation emitted by cell phones. The functional IF and other three elements were integrated in the composite cloth structure:

1. Basic fabric from the blend of: wool $(53 \%)$, polyester $(43 \%)$ and elastane $(4 \%)$, unit weight $184 \pm 5 \mathrm{~g} / \mathrm{m}^{2}$ supplied by a company Varteks, Croatia.

2. Adhesive interlining fabric made of polyester $(100 \%)$, unit weight of $83 \pm 5 \mathrm{~g} / \mathrm{m}^{2}$, supplied by Kufner, Germany.

3. Interlining fabric (IF) to be sewn, consisting of polyamide filaments $(100 \%)$ coated with copper $(\mathrm{Cu})$, unit weight of $52 \pm 5 \mathrm{~g} / \mathrm{m}^{2}$ supplied by Kufner, Germany.

4. Lining fabric made of viscose (100\%), unit weight of 72 $\pm 5 \mathrm{~g} / \mathrm{m}^{2}$ supplied by a company Varteks, Croatia.

The composite cloth structure $(F)$ was prepared in four technological phases under controlled conditions as follows: phase 1) adhesive interlining fabric was bonded to the reverse side of the basic fabric employing the process of fusing, under pressure of $5.8 \mathrm{~N} / \mathrm{cm}^{2}$, temperature $121{ }^{\circ} \mathrm{C}$ and duration of $18 \mathrm{~s}$.

phase 2) Sewing of fused structure with the shield interlining fabric and lining fabric.

phase 3) The composite cloth structure was ironed using an electro-steam iron, at the temperature of $200{ }^{\circ} \mathrm{C}$, lasting for $14 \mathrm{~s}$.

phase 4) After ironing two pressing cycles were performed using a machine by Brisay, precisely following the protocol used to manufacture men's jackets, under the temperature $140{ }^{\circ} \mathrm{C}$, pressure $40 \mathrm{~N} / \mathrm{cm}^{2}$ and steaming time $6 \mathrm{~s}$.

Dry cleaning process with the solvent perchlorethylene (PERC) is applied for care of the composite structure. The process was performed in a two - bath procedure with special detergent formulated with new, more biodegradable cationic surfactants intended for the antistatic effects and good cleaning effect $(\mathrm{w}=2 \%)$ added in the first PERC bath, as shown in Table 1. The composite cloth structure was dry cleaned through 10 cycles and interphase ironed at $110^{\circ} \mathrm{C}$.

Table 1. Dry cleaning process

\begin{tabular}{lccc}
\hline \multicolumn{1}{c}{ Parameters } & $\mathbf{1}^{\text {st }}$ bath & $\mathbf{2}^{\text {nd }}$ bath & Drying \\
\hline & Pre-cleaning & Cleaning & \\
Temperature $\left[{ }^{0} \mathrm{C}\right]$ & 20 & 20 & 60 \\
Time [min] & 4 & 6 & $30(5 / 5)$ \\
{$\left[\mathrm{min}^{-1}\right]$} & 300 & 360 & - \\
PERC $[1]$ & 20 & 40 & - \\
Detergent & $2 \%$ & - & - \\
Bath ratio (BR) & $1: 2$ & $1: 4$ & - \\
\hline
\end{tabular}

\subsection{Methods}

The electromagnetic interference (EMI) - The measuring setup for evaluation of SE properties (Fig. 1) of textiles was designed at the University of Zagreb, Faculty of Electrical Engineering and Computer Sciences, at the Microwave laboratory, Department of Radiocommunications following the recommendations of the international standards IEESTD 299-97, MIL STD 285 and ASTM D-4935-89. This measuring setup consists of a HP 8350 B signal generator, an IEV horn antenna - A12 type and a measuring instrument spectrum analyzer NARDA SRM 3000. Horn antenna has resonant frequency at $2.1 \mathrm{GHz}$ and gain on this frequency of $13.4 \mathrm{dBi}$. The aperture size of horn antenna is $21 \mathrm{~cm} \times 21 \mathrm{~cm}$. This horn antenna was at frequencies of 1.8 $\mathrm{GHz}$ and $2.4 \mathrm{GHz}$, while for $900 \mathrm{MHz}$, calibrated dipole antenna was used. The frame used was made of wood in order not to interfere with the electromagnetic field. There were no metallic objects in the vicinity of measurements. The specimen dimensions were $1 \mathrm{~m} \times 1 \mathrm{~m}$ and the distance 
between transmitting and receiving antennas were $30 \mathrm{~cm}$, as required by the standards. Prior to the measurements, calibration was done using metallic conductor placed in the wooden frame (for total reflection of the incident wave) and empty frame (total transmission of the incident wave). Both the antenna and the measuring instruments were facing each other. The position of the composite structure in the measuring setup is presented in Fig. 1.
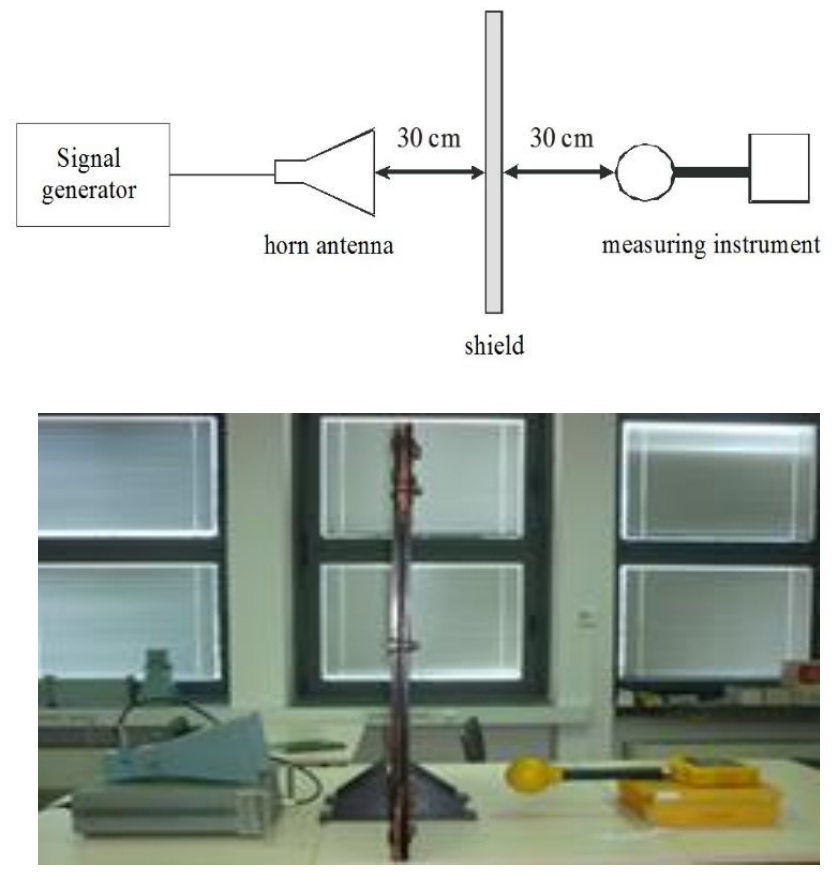

Figure 1. Measurement setup

SE properties of the composite cloth structure $(\mathrm{F})$ from different technological phases in the dimensions of $1 \times 1 \mathrm{~m}$ was measured according to the related standards [23-25]. The electrical fields measurements under frequencies 0.9 $\mathrm{GHz}, 1.8 \mathrm{GHz}, 2.1 \mathrm{GHz}$ and $2.4 \mathrm{GHz}$ of the composite structure was conducted before ironing and pressing $(\mathrm{F})$, after ironing and pressing (0) and after the first (1), third (3), fifth (5), seventh (7) and tenth (10) dry cleaning cycles measured on the face and reverse side.

Shield (composite barrier) effect (SE $(\mathrm{dB})$ ) was calculated according to the following equation

$$
\frac{S E=20 \log E_{0}}{E_{1}}
$$

where $E_{0}$ is the level of the received field without shield and $E_{1}$ is the level of electric field with shield.

Scanning electron microscopy (SEM) - The scanning electron microscope FE-SEM MIRA/LMU, Tescan was used for examination of cross section of the interlining fabric with copper. The samples were fixed on the holder and sputter-coated with a palladium-gold alloy. The samples were examined using signals produced by SEM secondary electrons (SE) with acceleration voltage of 10.0 $\mathrm{kV}$. The percentage of specific elements was detected through chemical analysis of interlining fabrics by Energy Dispersive Spectroscopy (EDS), Bruker AXS Microanalysis $\mathrm{GmbH}$.

\section{RESULTS AND DISCUSSION}

\subsection{Shield effect (SE)}

Previous investigation proved that functional interlining polyamide fabric coated with copper possesses SE properties [26]. It was found that SE properties of a interlining fabric after dry cleaning were dramatically reduced by a solvent and mechanical agitation that cracked a surface and impact on SE drop. The aim of this investigation was to observe SE durability of functional interlining fabric integrated in the composite cloth structure upon heat, moisture and solvent expo-sure. SE of the composite cloth structure (F) evaluated, from face and reverse side, before ironing and pressing, after ironing/pressing (0) and after the first (1), third (3), fifth (5), seventh (7) and tenth (10) dry cleaning cycles in the frequency range from $0.9 \mathrm{GHz}$ to $2.4 \mathrm{GHz}$ are shown in Figs. 2-5.

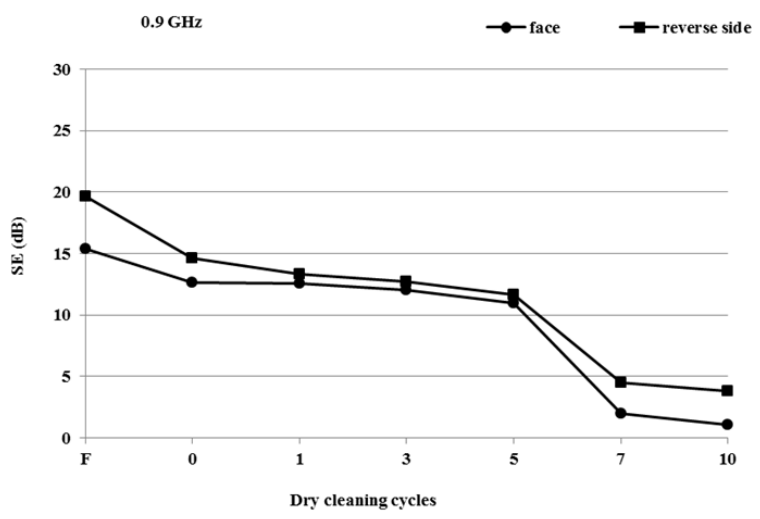

Figure 2. SE measurement results of the face and the reverse side of the composite cloth structure at the frequency of 0.9 $\mathrm{GHz}$

Fig. 2 shows SE of the cloth composite structures from face and the reverse side at the frequency of $0.9 \mathrm{GHz}$. The SE value of the composite structure $(\mathrm{F})$ face prior to solvent exposure in dry cleaning was $15.37 \mathrm{~dB}$. Additional ironing and double pressing (0) under manufacturing conditions caused a drop in SE $(12.65 \mathrm{~dB})$. The SE was stable throughout the five dry cleaning cycles. Considerable drop occurred between the fifth and the seventh cycle, where SE of the composite structure after the seventh cycle was around $2 \mathrm{~dB}$. SE value of the composite structure reverse side after ironing and double pressing as reduced from $19.66 \mathrm{~dB}$ to $14.64 \mathrm{~dB}$. Solvent in dry cleaning caused no further drastic drop after the first, third and fifth dry cleaning cycle. The decline was pronounced after the seventh cycles, when the SE value was brought to $4.49 \mathrm{~dB}$. 


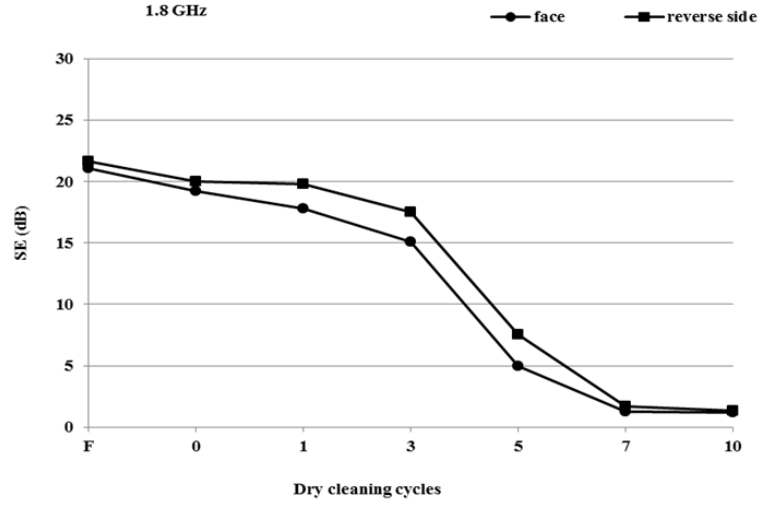

Figure 3. SE measurement results of the face and the reverse side of the composite cloth structure at the frequency of 1.8 $\mathrm{GHz}$

Fig. 3 shows for SE of the cloth composite structures from face and the reverse side at the frequency of $1.8 \mathrm{GHz}$. Ironing and double pressing (0) of the face side caused a drop in SE value from $21.07 \mathrm{~dB}$ to $19.21 \mathrm{~dB}$. Shield effect (SE) was stabilised until the third dry cleaning cycle at $15.06 \mathrm{~dB}$. It dropped considerably after the fifth dry cleaning cycle to $4.96 \mathrm{~dB}$. The drop continued so that after the seventh dry cleaning cycle it was only $1.25 \mathrm{~dB}$. It indicated on poor durability of the composite structure SE protective properties upon solvent exposure.

There was no significant reduction of SE of cloth reverse side after ironing and double pressing (from $21.63 \mathrm{~dB}$ to $19.98 \mathrm{~dB}$ ). After the third dry cleaning cycle the SE vale was drastically reduced from $17.51 \mathrm{~dB}$ to $7.51 \mathrm{~dB}$. Further decline was significant until the seventh cycle, while the values were stable from the seventh to the tenth cycle.

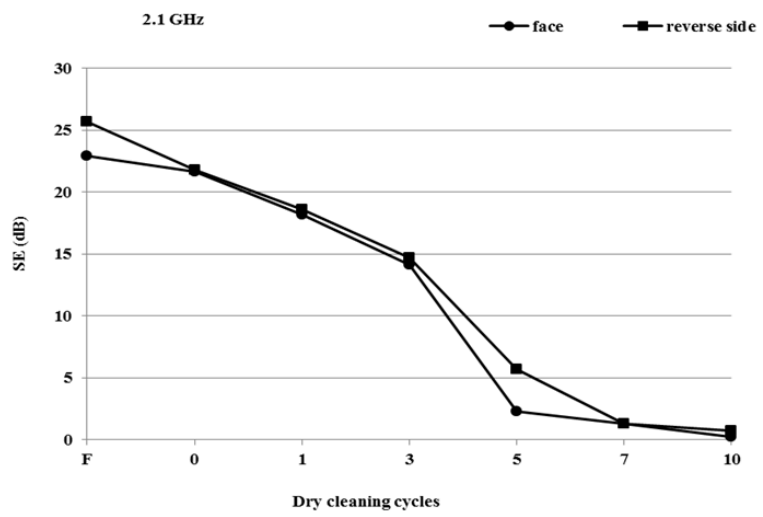

Figure 4. SE measurement results of the face and the reverse side of the composite cloth structure at the frequency of 2.1 $\mathrm{GHz}$

Fig. 4 shows a considerable drop in SE value of a face until the third dry cleaning cycle $(14.14 \mathrm{~dB})$. After the fifth cycle, SE was only $2.29 \mathrm{~dB}$, meaning that protective properties of the composite structure were almost completely lost at the frequency of $2.1 \mathrm{GHz}$. Fig. 4 shows a considerable impact of heat and moisture in ironing and double compressing on drop of SE the composite structure from reverse side, from $25.67 \mathrm{~dB}$ to $21.81 \mathrm{~dB}$ at the frequency of $2.1 \mathrm{GHz}$. After the third dry cleaning cycle, the $\mathrm{SE}$ value was reduced to $14.72 \mathrm{~dB}$ and to $5.68 \mathrm{~dB}$ after the fifth cycle. After the seventh cycle of dry cleaning, the value was $1.29 \mathrm{~dB}$, which means that the shield effect was almost completely lost.

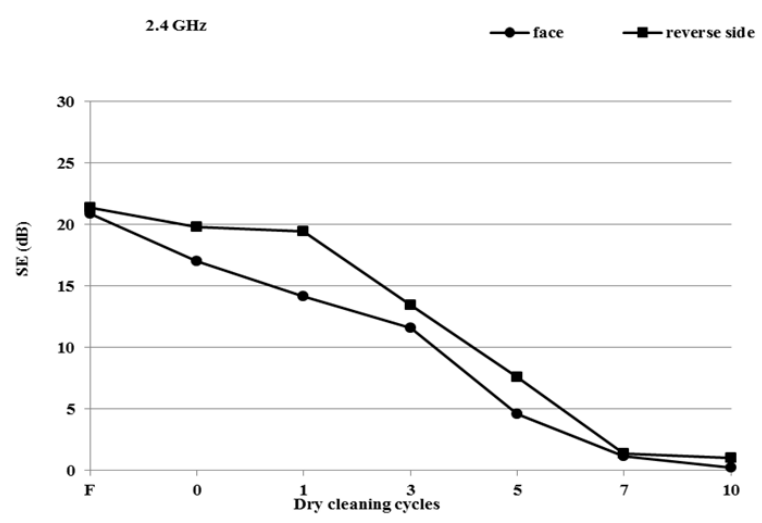

Figure 5. SE measurement results of the face and the reverse side of the composite cloth structure at the frequency of 2.4 $\mathrm{GHz}$

SE values of the cloth composite structures from face and the reverse side at the frequency of $2.4 \mathrm{GHz}$ showed in Fig. 5 dropped exponentially after the third, fifth and seventh cycle. SE of the composite cloth structure after 10 cycles was minor, or almost completely reduced.

Curves in Fig. 5 proved good durability of SE values from the reverse side on ironing and double pressing as well on the first cycle of dry cleaning. The SE values were reduced after the third cycle to $13.47 \mathrm{~dB}$, after the fifth to $7.58 \mathrm{~dB}$ and after the seventh cycle of dry cleaning to $1.39 \mathrm{~dB}$, meaning on low durability of SE properties on dry cleaning cycles.

\subsection{SEM Analysis}

SEM analysis of interlining fabric with copper was achieved through cross section and chemical analysis by EDS before and after 10 dry cleaning cycles. It is important to take into account that a micrograph and metal content was analysed on very small observed area (green highlighted). Cross section SEM images of interlining fabric coated with copper and content of copper $(\mathrm{Cu})$, carbon (C) and oxygen (O) before and after ten dry cleaning cycles are presented in Tab 2. The results of chemical analysis presented in Tab 2 indicated on a copper, carbon and oxygen content in SE protective IF. Copper content on IF after dry cleaning was reduced for app $2 \%$. It is obvious that reduction of copper content in IF after 10 dry cleaning cycles is not so high, what can be explained by position of IF in the composite structure, that was placed between basic fabric, adhesive IF and lining fabric. 
Table 2. Cross section and EDS chemical analysis of IF before and after 10 dry cleaning cycles

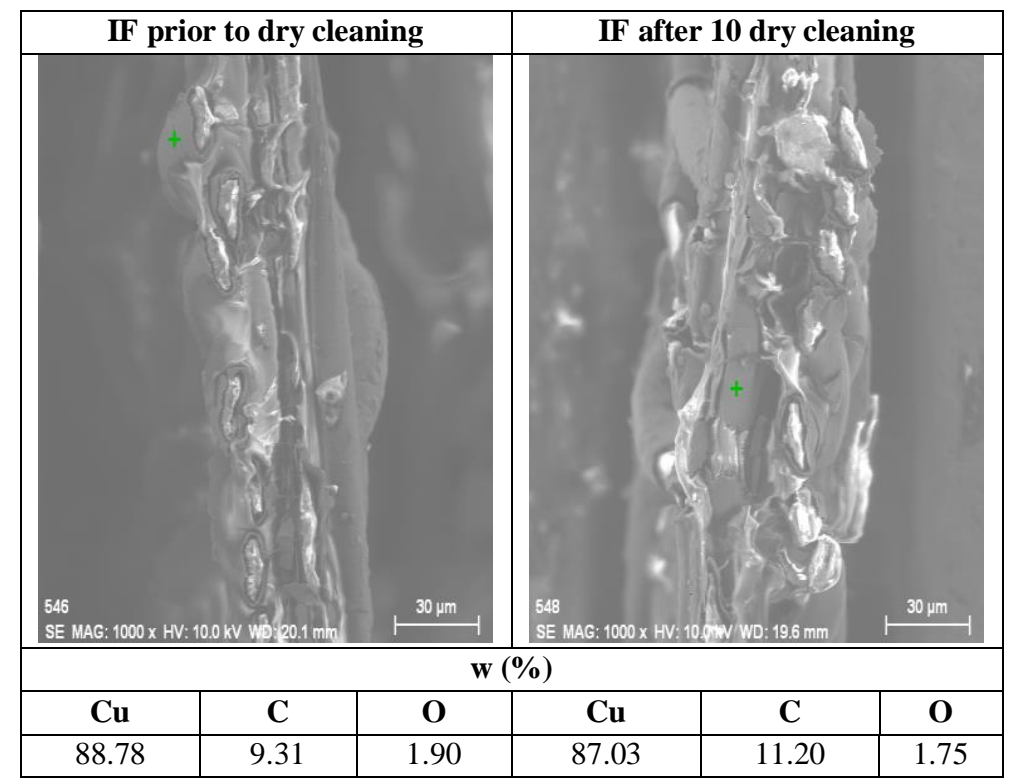

According to this position, functional IF was protected from direct impact of mechanical agitation in dry cleaning process.

\section{CONCLUSION}

Shield effect properties of the composite cloth structure, as an integral part of men's jacket before and after exposure to heat and moisture in ironing and double pressing as well as solvent in dry cleaning were investigated. The structure included a built-in functional interlining fabric, which exhibited shield effect properties, due to a copper layer on both warp and weft filament yarns. The results of SE indicated an initial drop of shield effect in the garment processing already, namely after thermal and mechanical

\section{REFERENCES}

1. Malarić, K. (2010). EMI Protection for Communication Systems, Boston, USA, Artech House, 685 Canton Street, Norwood, MA 02062 .

2. Ammari, M., Lecomte, A., Sakly, M., Abdelmelek, H., \& de-Seze, R. (2008) Exposure to GSM $900 \mathrm{MHz}$ Electromagnetic Fields Affects Cerebral Cytochrome Coxidase Activity, Toxicology, 250 (1), pp. 70-74.

3. Sage, C., \& Carpenter, D. O.,(2012, December). "A Rationale for Biologically-based Exposure Standards for Low-Intensity Electromagnetic Radiation”, BioInitiative, USA.

4. Shahin, S., Banerjee, S., Singh, S.P., \& Chaturvedi, C.M. (2015) "2.45 GHz Microwave Radiation Impairs Learning and Spatial Memory via Oxidative, Nitrosative Stress Induced p53Dependent/Independent Hippocampal Apoptosis: Molecular Basis and Underlying Mechanism", Toxicol Sci, 148, pp. 380-399.

5. Shangcheng, X., Zhou, Z., Lei, Z., Zhengping, Y., Wei, Z., Yuan, W., and Min, Z., (2010). "Exposure to $1800 \mathrm{MHz}$ Radiofrequency Radiation Induces Oxidative Damage to Mitochondrial DNA in Primary Cultured Neurons", Brain Research, 1311, pp. 189-196.

6. Ahamed, V. I., Karthick, N.G., \& Joseph P.K., (2008). "Effect of Mobile Phone Radiation on Heart Rate Variability", Computers in Biology and Medicine 38 (6), pp. 709-712 actions of ironer and press. Further SE decrease was influenced by solvent and mechanical agitation in dry cleaning of the composite structure. Poor durability of SE properties in dry cleaning was not completely harmonized with SEM micrographs of cross section and chemical analysis. Although only $2 \%$ of the copper was lost in the dry cleaning procedure, there was a discontinuation in some places of copper which caused the weaker shielding function.

\section{ACKNOWLEDGMENT}

This work has been supported in part by Croatian Science Foundation under project HRZZ-IP-2018-01-7028.

7. Manzetti, S., \& Johansson, O. (2012). Global electromagnetic toxicity and frequency-induced diseases: theory and short overview. Pathophysiology, (19), pp.185-191.

8. Politanski, P., Bortkiewicz, A., \& Zmyslony, M. (2016) Effects of radio- and microwaves emitted by wireless communication devices on the functions of the nervous system selected elements. Med Pr, 67. pp. 411-421

9. Vanderstraeten, J., (2009). GSM Fields and Health: an Updated Literature Review, Rev Med Brux, 4, pp. 416-424.

10. Ozen, M. S., Usta, I., Beyit, A., Uzun, M., Sancak, E., \& Isgoren, E. (2012, July). An Investigation of Electromagnetic Wave Absorption Potential of Woven Fabrics with Stainless Steel Wire, RMUTP International Conference Textiles \& Fashion 2012, Bangkok, Thailand.

11. Duran, D., \& Kadoglu, H. (2012). A Research on Electromagnetic Shielding with Copper Core Yarns, Tekstil ve Konfeksiyon, (4), pp. 354-359.

12. Brzezinski, S., Rybicki, T., Karbownik, I., Malinowska, G., Rybicki, E., Szugajew, L., Śledzińska, K., (2009). Textile Multi-layer Systems for Protection Against Electromagnetic Radiation, Fibres \& Textiles in Eastern Europe, 73, 17 (2), pp. 66-71. 
13. Koprowska, J., Pietranik, M., \& Stawski, W. (2004). New Type of Textiles with Shielding Properties, Fibres \& Textiles in Eastern Europe, 12 (3), pp. 39-42.

14. Ceken, F., Kayacan, O., Ozkurt, A., \& Ugurlu, S. S. (2011). The Electromagnetic Shielding Properties of Copper and Stainless Steel Knitted Fabrics, Tekstil, 60 (7), pp. 295-354.

15. Ceken, F., Pamuk, G., Kayacan, O., Ozkurt, A., Ugurlu, S. S. (2012) Electromagnetic Shielding Properties of Plain Knitted Fabrics Containing Conductive Yarns, Journal of Engineered Fibers and Fabrics, 7 (4), pp. 81-87.

16. Sonehara, M., Noguchi, S., Kurashina, T., Sato, T., Yamasawa, K. \& Miura, Y. (2009). Development of an Electromagnetic Wave Shielding Textile by Electroless Ni-Based Alloy Plating, IEEE Transactions on Magnetics, 45 (10), pp. 4173-4175.

17. Duran, D., \& Kadoglu, H. (2010, October). Protection Against Electromagnetic Waves with Textiles, Book ogf Proceedings 5th International Textile, Clothing \& Design Conference - Magic World of Textiles, Dubrovnik, Croatia, pp. 231-234.

18. Ozdemir, H., \& Ozkurt, A., (2013). The Effects of Fabric Structural Parameters on the Electromagnetic Shielding Effectiveness, Tekstil, 62 (3-4), pp. 134-144.

19. Das, A., Kothari, V. K., Kothari, A., \& Kumar, A. (2009) Effect of Various Parameters on Electromagnetic Shielding Effectivenes of Textile Fabrics, Indian Journal of Fibers \& Textile Research, 34 (6), pp. 144-148.
20. Cheng, K. B., Cheng, T. W., Nadaraj, R. N., Giri Dev, V. R., \& Neelakandan, R. (2006). Electromagnetic Shielding Effectiveness of the Twill Copper Woven Fabrics, Journal of Reinforced Plastics and Composites, 25 (7), pp. 699-709.

21. Sonehara, M., Sato, T., Takasaki, M., \& Konishi, H. (2008) Preparation and Characterization of Nanofiber Nonwoven Textile for Electromagnetic Wave Shielding, IEEE Transactions on Magnetics, 44 (11), pp. 3107-3110.

22. Tunakova, V., Technikova, L. \& Militky, J. (2017) Influence of washing/drying cycles on fundamental properties of metal-fiber contained fabric designed for electromagnetic shielding purposes, Textile Research Journal, 87 (2) pp. 175-192.

23. ASTM D-4935-89 Standard Test Method for Measuring the Electromagnetic Shielding Effectiveness of Planar Materials, 1999.

24. IEEE STD 299 Standard Method for Measuring the Effectiveness of Electromagnetic Shielding Enclosures, 299, 2006.

25. MIL-STD-285, Military Standard: Attenuation Measurements for Enclosures, Electromagnetic Shielding, 1956.

26. Šaravanja, B., Malarić, K., Pušić, T., Ujević, D. (2015) Shield Effect of Functional Interlining Fabric, Autex Research Journal, 15 (2) pp. 93-98. 